\title{
Mulheres insurgentes na guerra de Independência mexicana
}

\author{
Romilda Costa Motta ${ }^{1}$
}

GUZMÁN PEREZ, Moisés et. al. Mujeres insurgentes. México D. F.: Senado de la República/Siglo XXI Editores, 2010. 277 p.

\begin{abstract}
¿Por qué tan obstinada persecución contra mí? Tengo derecho a hacer cuanto pueda a favor de mi patria, porque soy mexicana. No creo cometer ninguna falta con mi conducta, sino cumplir con mi deber.
\end{abstract}

Luisa Martínez

Confiese V., Sr. Alamán que no sólo el amor es el móvil de las acciones de las mujeres: que ellas son capaces de todos los entusiasmos, y que los deseos de la gloria y de la libertad de la patria no les son unos sentimientos extraños; antes bien, suellen obrar en ellas con más vigor, como que siempre los sacrificios de las mujeres (...) son más desinteresados, y parece que no buscan más recompensas de ellos, que la de que sean aceptadas (...). Por lo que mí toca, sé decir que mis acciones (y) opiniones han sido siempre mui libres, nadie ha influido absolutamente en ellas, y en este punto he obrado siempre con total independencia, y sin atender a las opiniones que han tenido las personas que he estimado. Me persuado que así serán todas las mujeres, exceptuando a las muy estúpidas y las que por efecto de su educación hayan contraído un hábito servil.

Leona Vicario

O ano de 2010 foi emblemático para os mexicanos, pois concentrou comemorações ligadas a dois grandes marcos fundadores da história nacional: o bicentenário da Independência e o centenário da Revolução. Partindo da compreensão de que um povo não pode prescindir de seu passado, tais comemorações evidenciaram esse pensamento. Como parte dos festejos, o Senado mexicano lançou, ainda em 2008, um concurso que desafiava historiadores e demais pesquisadores a produzirem ensaios sobre as duas grandes efemérides da história mexicana. Foram apresentadas como proposta as seguintes temáticas: a construção do México; a identidade nacional; independência e soberania; mulheres insurgentes; mulheres revolucionárias e demandas e conquistas da Revolução. A maioria dos textos recebidos tratava da participação feminina nos dois eventos. Cremos que isso se justifique pela patente constatação da necessidade de que a historiografia avance no sentido de dar o lugar devido não apenas às mulheres, mas também a outros grupos considerados subalternos, como os indígenas,

\footnotetext{
${ }^{1}$ Doutoranda do Programa de História Social da Universidade de São Paulo. Desenvolve o projeto Em busca de liberdade. A escrita autobiográfica de duas latino-americanas: Antonieta Rivas Mercado e Patrícia Galvão (Pagu), sob orientação da prof dr $^{\mathrm{a}}$ Maria Ligia Coelho Prado e com apoio financeiro da CAPES. Contato: romildamotta@usp.br
}

Revista Eletrônica da ANPHLAC, n.11, p. 160-167, jul./dez. 2011. http://revista.anphlac.org.br/index.php/revista 
os negros, entre outros, que tiveram sua participação e resistência silenciadas, ou diminuídas, na narrativa oficial dos grandes eventos históricos, aceitando, muitas vezes, a subordinação que lhes foi imposta por meio do emprego da violência simbólica. Cabe, contudo, ressaltar que houve mais ensaios sobre a Independência do que sobre a Revolução. E, infelizmente, entre os contemplados para a publicação, não foi selecionado nenhum que discorresse acerca da participação feminina na Revolução Mexicana.

A presente obra, Mujeres insurgentes, compõe-se de cinco ensaios. Os dois vencedores foram: "Mujeres de amor y guerra. Roles femeninos en la Independencia de México", escrito pelo historiador Moisés Guzmán Pérez (professor na Universidade Michoacana de San Nicolás de Hidalgo) e "“Por no haber una mujer que no sea una berdadera insurgenta'. Hacia una historia de la participación femenina en la Guerra de Independencia”, pela antropóloga Rosío Córdova Plaza (investigadora do Instituto de Investigaciones Histórico-Sociales da Universidade Veracruzana). Os demais ensaios publicados receberam menções especiais. São eles: "Antonina Guevara. Encrucijada y destino de una mujer en la insurgencia de la América mexicana”, por Eduardo Miranda Arrieta (do Instituto de Investigaciones Históricas da Universidade Michoacana de San Nicolás de Hidalgo); “Entre la persecución y la muerte. Las mujeres insurgentes”, por Jaime Olveda Legaspi (de El Colegio de Jalisco); e "Pocos nombres conocidos, muchos ignorados. La participación de la mujer en el movimiento de Independencia”, por María Elena Valadez Aguillar (licenciada em Economia e História pela Universidade Autônoma do México).

É sabido que os dois lados em combate, realistas e insurgentes, contaram com as simpatias e a participação de mulheres diversas: nobres, plebeias, espanholas, criollas, das castas, indígenas. Pode-se afirmar que os autores dos ensaios selecionados são unânimes em admitir que as mulheres foram peças-chave na guerra, mas, apesar dessa inegável presença e do alto custo pelo seu envolvimento - execuções, encarceramentos, deportações, humilhações, confisco de propriedades e outras tantas punições -, todos reconhecem as dificuldades, uma vez mais, de se escrever uma história que incorpore e valorize a participação de mulheres no processo histórico. Por uma série de motivos, as fontes disponíveis limitam a reconstituição dos fatos silenciando-as. 
A leitura dos documentos levou cada um dos autores a privilegiar aspectos diferenciados na abordagem: o individual ou o coletivo, mulheres de elite ou mulheres do povo, bem como análises interpretativas que problematizaram, ora mais ora menos, as fontes escolhidas. De todo modo, ao longo das páginas, é possível encontrar descrições e análises da participação de inúmeras mulheres que se comprometeram num dos maiores acontecimentos da história mexicana: a guerra pela Independência. Figuram desde as mais conhecidas pela historiografia, citadas com nome e sobrenome pelos cronistas da época, como Leona Vicário, Mariana Martínez, Gertrudis Bocanegra, que sintetizou todos os crimes que podiam ser praticados por uma mulher (sedutora de tropa, mensageira, financiadora e participante ativa nas batalhas), María Josefa Martínez Navarrete, Josefa Ortiz Domínguez, María Manuela Molina (La Barragana) ou María Andrea Martínez (La Campanera), até outras que se tornaram conhecidas simplesmente por seus apelidos, como "La Guanajuatena" e "La Gabina", ou ainda aquelas que atuaram na guerra civil, mas permaneceram no completo anonimato.

O primeiro e maior ensaio da obra foi escrito pelo historiador Moisés Guzmán Pérez. O autor faz um rico levantamento das fontes, apurando nomes e participações femininas na guerra. Como resultado, aponta uma diversidade de papéis por elas exercidos: na organização de tertúlias - espaços de sociabilidade, consciência e ação política para as mulheres da elite criolla —, já que era, nesses encontros, entre um chá e outro, que se planejava a insurgência, também como propagandistas, conspiradoras e espiãs, mensageiras e informantes da insurreição, como companheiras de armas, prostitutas, amantes e sedutoras, e ainda como impressoras. Guzmán Pérez ressaltou que, nos discursos historiográficos no México, assim como em grande parte do continente americano, prevaleceram visões "sexistas" e "racistas", em que a figura masculina foi predominante na construção do panteão dos "heróis nacionais". Desenvolvendo essa afirmação, o autor se refere a estudos realizados por outros pesquisadores que sublinham o fato de que, em parte da documentação existente, quando as mulheres ocupam um lugar privilegiado nas narrativas, observa-se, especialmente, a presença daquelas oriundas do estrato social elevado ou, no quesito racial, das de "qualidade espanhola" — ainda que se saiba que a maioria das mulheres partícipes tenham sido integrantes de setores étnicos e sociais marginais da sociedade.

Embora a análise de Guzmán Pérez tenha chamado a atenção para tais questões, além de ressaltar, em parte das fontes escolhidas, o lado combativo de muitas mulheres 
nos campos de batalhas, o autor, no decorrer de seu texto, termina por assumir uma perspectiva mais tradicional, enaltecendo a atuação daquelas que, em "silêncio" e com profundo "amor", “devoção" e "abnegação", seguiram seus esposos, cuidaram de seus filhos, dos doentes e lhes foram fiéis até a morte (p. 21). Em suas conclusões, o autor resume os motivos que teriam levado as mulheres a se envolverem no movimento armado a dois valores: a religião e o amor ao marido, a quem entregaram a vida e juraram fidelidade no altar (p. 90). Também, ao indicar as percepções que as mulheres tinham de si mesmas e o que lhes ocorreu após a guerra de Independência, o autor avança pouco. Retira a atuação feminina da esfera pública e a devolve à esfera doméstica, afirmando, de forma sucinta, que as mulheres voltaram para casa e retomaram suas atividades associadas ao interior do lar, já que "não tinham ambições políticas", como se sua participação tivesse sido em vão ou não fosse relevante discutir os porquês de tais encaminhamentos.

Eduardo Miranda Arrieta foi o único que optou por contemplar a história de uma personagem isolada: Antonina Guevara, mulher de Nicolás Bravo, um dos líderes da insurgência. $\mathrm{O}$ texto de Miranda Arrieta nos permite acompanhar a impressionante trajetória de Bravo, que atuou desde o início da insurgência, quando Morelos ainda estava na liderança. Mais tarde, Bravo passou alguns anos preso e voltou às armas ao lado de Agustín de Iturbide e Vicente Guerrero, até alcançarem juntos a Independência do México. Enfim, participou de acontecimentos políticos de seu país até próximo a 1850, quando então se encontrava cansado para se envolver em novas batalhas. Miranda Arrieta sublinha que, diferentemente de Leona Vicário, mulher de Andrés Quintana Roo, que teve atuação aberta e ativa nos campos de batalha e nos espaços políticos, Antonina Guevara participou "silenciosamente no processo revolucionário da América mexicana" (p. 148). Além dos arquivos oficiais, o autor considerou cartas trocadas entre Antonina Guevara e Nicolás Bravo, nas quais é possível observar sua participação transmitindo mensagens de Bravo aos líderes que se encontravam em liberdade. Entretanto, não há como deixar de notar que Antonina passa quase que tangencialmente pela narrativa dos acontecimentos. $\mathrm{O}$ autor reconhece que, nas fontes, a exemplo de tantas outras mulheres, "Antonina quase não se escuta, pouco se vê" (p. 181 e 184). Enquanto os fatos da vida de Bravo são descritos ocupando um espaço muito maior que o de sua mulher, Antonina segue seu "destino abnegado", esperando o marido, ao lado da inseparável sogra, com "elevada lealdade e devoção". 
Ainda que, numa tentativa de mostrar que as mulheres tinham consciência política de seus atos, Miranda Arrieta tenha incluído o contundente trecho da resposta de Leona Vicário a Lucas Alamán (citado na epígrafe), após ser acusada de que seu único patriotismo havia sido abandonar a casa para seguir um "amante" (seu esposo), o autor privilegiou a análise de uma mulher que participou "silenciosamente", mantendose em "um âmbito mais discreto, do lar, mas contribuindo sempre com os afãs de seu companheiro" (p. 153).

Já a análise de Rosío Córdova Plaza demonstra preocupação maior com a perspectiva de gênero, ao ressaltar o fato de que a história se escreve a partir do poder. Nesse sentido, ela cita Joan W. Scott que afirma que a história não só é necessariamente incompleta, mas também o uso e a interpretação das fontes são oblíquos e parciais (p. 102).

A autora faz uma abordagem que examina as mudanças flagradas no levantamento da vida feminina. Avalia as normas culturais vigentes na sociedade da época, pautadas em características corporativas, etnicamente segregadas e altamente hierarquizadas, e que, portanto, caracterizavam as mulheres como um grupo subordinado, ignorando ou desprezando seu desempenho em âmbitos não contemplados como propriamente femininos, e, assim, percebendo seu exercício de poder como inexistente ou ilegítimo. Essa antropóloga ressalta a necessidade de se levar em conta o fato de que, para os testemunhos, atores ou cronistas da época, não carecia registrar ou reconhecer o papel desempenhado por mulheres, sobretudo, numa arena em que se concebia como "verdade" a incapacidade de atuação feminina. Córdova Plaza lembra também que a guerra, como um período de exceção, provocou fissuras na ordem social. Assim, aqueles momentos de anormalidade não só relaxaram a vigilância social sobre as atividades femininas, mas também permitiram alterar o equilíbrio de poder entre os gêneros, de forma que as mulheres conseguissem ascender a espaços e atividades reservados tradicionalmente aos homens.

Rosío Córdova Plaza discute ainda alguns recursos dos quais algumas mulheres lançaram mão a partir de sua particular condição de gênero, e que, por vezes, lhes permitiram ocultar atividades ou mesmo livraram-nas da morte. A maternidade, por exemplo, eximiu algumas da forca ou do fuzilamento. Outra "arma" comumente utilizada pelas mulheres em seus depoimentos era a apropriação das concepções a respeito da ignorância, incapacidade intelectual ou falta de compreensão da política. Ao 
serem interrogadas, negavam acusações, justificando-se como "frágeis", "indefesas", ou, diante do inegável, apontavam a "debilidade do nosso sexo", para alegar inocência, argumentando impossibilidade de influenciar opiniões de homens ou parentes. Enfim, muitas delas tiraram proveito da perspectiva de gênero vigente na época: exacerbaram ao máximo as características atribuídas à feminilidade e manipularam a imagem cristalizada para continuarem incursionando nos espaços públicos de maneira versátil. Em determinadas ocasiões, a estratégia funcionou. Em outras, quando o envolvimento de algumas na insurgência era incontestável, pagaram com a vida.

Ao discutir as questões ligadas às marcas frágeis e apagadas da participação feminina na guerra, presentes na documentação, Córdova Plaza vai além, problematizando as razões para tal invisibilidade. A autora lembra que é importante pensar nos mecanismos colocados em marcha, com seus aparelhos ideológicos e repressivos - Igreja, família e Estado -, para suprimi-las da história. Sabemos que esse processo sublinhado pela autora também se deu mediante o resgate de algumas poucas "heroínas", criando a chamada "síndrome da grande mulher" que acentua o anonimato de muitas outras.

Os dois últimos autores trazem sua contribuição ao explorar a análise em torno da participação de nomes menos conhecidos pela historiografia. Privilegiaram a atuação de mulheres que quebraram barreiras envolvendo-se em atividades fora dos cânones de seu papel convencional de gênero.

O texto de María Elena Valadez Aguillar apresenta a atuação de mulheres que, movidas por verdadeira fascinação e sedução pela liberdade, decidiram participar abertamente da revolução de Independência, quebrantando, com prejuízos à imagem de submissão, obediência e fidelidade, tanto o rei como suas famílias. A autora faz questão de destacar que "escrever a história das mulheres é elevá-las ao patamar de sujeitos históricos", e defende que isso deve ser construído sem vitimá-las ou minimizá-las. Nesse sentido, critica abordagens que, ao reproduzirem simplesmente as versões dos documentos, terminam por vincular a mulher apenas como parte do "outro", ou seja, como mães, amantes, filhas, esposas ou irmãs dos grandes nomes masculinos. Ainda segundo Valadez Aguillar, a despeito da carga social, moral e religiosa do tempo vivido, várias dessas mulheres transgrediram normas, não permitindo que tais preceitos as impedissem de se comprometer de forma ativa e contundente com o movimento armado. Fizeram-no conscientemente: combatendo corpo a corpo, produzindo 
munições, transportando cartuchos, cuidando e atendendo feridos de guerra, e, em alguns casos, inclusive, com arrojo e valentia, conseguindo o comando de tropas, formadas por grupos de homens que lutaram e combateram sob seu mando.

Jaime Olveda Legaspi concentra sua análise especialmente nos casos de mulheres que foram consideradas atrevidas e perigosas por protagonizarem atos de violência coletiva. $\mathrm{O}$ autor problematiza um assunto específico, a saber, as "sedutoras de tropa", que constituíam um dos maiores números de casos envolvendo mulheres nos processos existentes. O historiador chama a atenção para o fato de que o ato da sedução trazia uma força política que não pode ser ignorada. Afinal, essas mulheres não seduziam os homens apenas sexualmente, mas eram principalmente suas palavras que os persuadiam a passarem ao partido dos rebeldes. Sobre o tema da "sedução de tropa", María Elena Aguillar assinala que, ao tipificar o ato de "crime", se atribuía à mulher a condição de prostituta, o que envolveria um problema de índole moral. Como as autoridades não podiam controlar ou combater o "uso dos atributos femininos", reputavam-nos uma grande ameaça, argumentando que a situação só seria dominada se fosse assegurado que a condição moral e sexual da mulher estivesse subordinada ao homem.

Conforme lembram os autores, embora os documentos de época insinuem a suposta inexistência da participação das mulheres na guerra, visando silenciá-las no processo, sabemos, por outro lado, que não só é possível como necessário rastrear alguns de seus atos, motivos e opiniões. Como já afirmou Maria Ligia Prado, ainda que se trate de fato pressupostamente esquecido ou ocultado, as mulheres envolvidas no movimento de Independência na América Latina atuaram "num circuito claramente identificado com o da política, motivadas por ideias, sentimentos e crenças que as levaram a romper com os padrões sociais e religiosos vigentes. Sua notável coragem especialmente nos momentos trágicos de prisão e condenação - indica que estavam preparadas para aceitar as consequências de suas escolhas".2

Historiadores que se concentram no campo da história das mulheres concordam que, para romper ou diminuir o profundo silêncio que as envolve, não basta acumular dados que evidenciem a presença e a participação femininas ativas nos acontecimentos históricos. É preciso que as análises e as interpretações construídas avancem no sentido

\footnotetext{
${ }^{2}$ PRADO, Maria Ligia Coelho. A participação das mulheres nas lutas de Independência política na América Latina. In: América Latina no século XIX. Tramas, telas e textos. 2 ed. São Paulo: Edusp, 2004. p. 51.
} 
de procurar entender os porquês da pouca transcendência, do esquecimento, ocultamento ou despolitização a que são reduzidas as ações das mulheres nos diferentes processos históricos.

Revista Eletrônica da ANPHLAC, n.11, p. 160-167, jul./dez. 2011. http://revista.anphlac.org.br/index.php/revista 